East African Medical Journal Vol. 80 No 2 February 2003

INFLUENCE OF SEMINAR AND MAILED GUIDELINES ON KNOWLEDGE OF SCHOOL TEACHERS REGARDING EMERGENCY TREATMENT FOR DENTAL INJURIES

F.K. Kahabuka, DDS, MSc, PhD, Senior Lecturer, Faculty of Dentistry, Department of Preventive and Community Dentistry, Muhimbili University College of Health Sciences, P.O. Box 65014, Dar es Salaam, Tanzania, M. van't Hof, BSc, PhD, Professor, W. Willemsen, DDS, PhD, Senior Lecturer and R. Burgersdijk, DDS, PhD, Professor, Medical Faculty, College of Dental Sciences, University of Nijmegen, Nijmegen, The Netherlands

Request for reprints to: Dr. F.K. Kahabuka, Faculty of Dentistry, Department of Preventive and Community Dentistry, Muhimbili University College of Health Sciences, P.O. Box 65014, Dar es Salaam, Tanzania

\title{
INFLUENCE OF SEMINAR AND MAILED GUIDELINES ON KNOWLEDGE OF SCHOOL TEACHERS REGARDING EMERGENCY TREATMENT FOR DENTAL INJURIES
}

\author{
F.K. KAHABUKA, M. VAN'T HOF, W. WILLEMSEN and R. BURGERSDIJK
}

\begin{abstract}
Objective: To evaluate the influence of two different modes for delivering guidelines on school teachers' knowledge on emergency treatment for dental injuries.

Design: Cross sectional questionnaire study.

Setting: Primary schools in Dar es Salaam city council in Tanzania.

Participants: Primary school teachers.

Intervention: Provision of guidelines by mail or through seminar or no guidelines (control).

Main outcome measures: Knowledge on emergency management of dental injuries Results: The teachers did not have adequate knowledge on the emergency management of traumatised teeth. Significant differences were observed between the study groups. Teachers from the seminar group were likely to re-implant an avulsed tooth (five times more likely than the control group) or otherwise would transport it in the recommended medium. No significant differences were observed between the groups on their willingness to take the avulsed tooth to a doctor or dentist or on the method or liquid they would use to clean a dirty avulsed tooth.

Conclusion: Compared to provision of information through mailed guidelines, seminar discussions better improved the school teachers' knowledge regarding emergency treatment for dental injuries.
\end{abstract}

\section{INTRODUCTION}

Investigations on dental trauma reveal that the lay public does not have adequate knowledge on the management of traumatised teeth(1-5). This information is unfavourable, because at best prompt and appropriate emergency management needs to be started by lay persons prior to the child's initial contact with a dental practitioner(6). Consequently, several authors(1-7) have recommended that educational campaigns about the management of dental trauma, particularly avulsed teeth, need to be provided to the lay community.

Prior to a study conducted by Moshy et al in 1996(8), Tanzanian dentists relied on literature from developed countries for issues related to facial injuries. Utilizing hospital data, Moshy(8) observed similar demographic trends of the facial injuries in Tanzania with that in developed countries. Unfortunately, in Tanzania there is no professional information to guide parents, teachers and children on what to do in the event of dental trauma. Hence, it was thought that schoolteachers could play a fundamental role in promoting self-care for children who sustain dental injuries. Preliminarily, investigation on school teachers' knowledge about the management of dental trauma was done among 539 randomly selected teachers from each of the three districts of Dar es Salaam. Results of the investigation showed that $34 \%-67 \%$ of the teachers had seen children who had sustained various dental injuries. A small percentage of the teachers (1\%) would reimplant the avulsed tooth, while 5\% would transport the avulsed tooth and 20\% would transport the avulsed tooth in milk or in saline solution. Thirty three per cent of the teachers reported that they would scrub to clean a dirty avulsed tooth and $22 \%$ would not take the avulsed tooth to a doctor or dentist. After a pilot survey, guidelines on what the lay community should do in the event of dental trauma were distributed to schools or were presented to teachers in a seminar session. The aim of this study was to evaluate the effect of the two modes of delivering the guidelines.

\section{MATERIALS AND METHODS}

A list of government owned primary schools was obtained from the Dar es Salaam city council $(n=180)$. On this list, names of schools and number of teachers at each school were indicated. Dar es Salaam has 5,757 teachers in its three districts: Kinondoni, Temeke and Ilala with $46 \%$, 
$30 \%$ and $24 \%$ of the teachers respectively. Primary schools in each district were divided into three study groups; a group from which teachers were invited to attend a seminar, $(n=62)$, a group in which the heads of school were mailed printed guidelines only $(n=58)$ and a control group that did not receive any guidelines $(\mathrm{n}=60)$.

A group that received mailed guidelines: Guidelines narrating steps to be taken by a lay public when a child sustains dental injury were prepared in accordance with the recommendations by Andreasen(6) and McTigue(9). The guidelines were translated into Kiswahili (the national language) and printed as a brochure. The cover of the brochure displayed a fractured tooth and a caption indicating that such a condition could be treated. The brochures were mailed to 64 government owned primary schools, which belonged to the mailed guidelines group or missed the seminar. Together with the brochure, was a covering letter requesting the heads of schools to convey the information comprised in the brochure to all teachers at their respective schools.

A group that attended a seminar: One hundred and twenty four teachers (two teachers from each school; the head of the school and a teacher responsible for health affairs) from 62 primary schools were invited to attend a one-day seminar. One hundred and twelve teachers (90\%) from 56 schools attended the seminar. Participants from six schools who missed the seminar were included in the mailed guidelines group. The seminar (an oral presentation with the aid of transparencies) was conducted at the Faculty of Dentistry by one author (FKK) in two sessions. Each session (with about 60 teachers) lasted around two hours. On registration, each participant was provided with a copy of the brochure. The facilitator elaborated on the steps to be taken by teachers whenever a child sustained an injury to dental tissues while at school and requested the teachers to disseminate the information to their colleagues. This study utilised the questionnaire, modified from that used in Australia by Raphael and Gregory(1).

During the preliminary survey, some teachers were not found at schools either due to illness, study leave or annual leave. Therefore, during the main study each school was considered to have only three quarters of registered teachers. A random selection of schools was done independently in each district until an approximate number of teachers required in each group was reached. The survey was voluntary and confidentiality was assured since names were not required on the questionnaire but respective groups were indicated. The results of the questionnaire were expressed as frequency distribution and computed in percentages. Chi-square test was employed to test the differences between the three study groups. $\mathrm{P}<0.05$ was chosen as the level of significance.

\section{RESULTS}

Evaluation of the influence of the two modes of provision of guidelines to schoolteachers was done six months after provision of guidelines. On a survey day, teachers who were present at schools were requested to fill in a self-administered close-ended questionnaire form. Except at three schools out of 25, all the questionnaires were filled and collected on the same day. From the three schools, $68-73 \%$ of the questionnaires were filled. Table 1 presents a total of 655 teachers who participated, showing that a proportional distribution of the participants over the districts and intervention modes was obtained. A substantial number of teachers reported to have seen children who had sustained dental injuries, with the percentages being $45 \%$ for soft tissue injuries, $66 \%$ for a fractured tooth, $76 \%$ for a knocked out tooth and $84 \%$ for periodontal tissue injuries. There were no significant differences between the three groups in the number of teachers who had seen children suffering from various dental injuries.

Of the teachers who filled in the questionnaire, $54 \%$ indicated that they would send a child who had sustained injury to dental tissues to a nearby dental clinic and $42 \%$ would send the child to a nearby hospital. Eighty seven per cent of the teachers reported that they would send the child who had sustained oral injuries immediately for professional consultation, while $12 \%$ of the teachers would reimplant the avulsed tooth (Table 2). In comparison to teachers in the other two groups, a highly significant difference $\left(X^{2}\right.$ test $\left.p<0.0005\right)$ was observed whereby more teachers from the seminar group (26\%) would reimplant a knocked out tooth compared to $4 \%$ from the mailed guidelines group and $6 \%$ from the control group.

\section{Table 1}

Distribution of schools and teachers over the study groups and districts in the evaluation study

\begin{tabular}{lcccc}
\hline & $\begin{array}{c}\text { Total } \\
(\mathrm{n}=655)\end{array}$ & $\begin{array}{c}\text { Seminar } \\
(\mathrm{n}=272)\end{array}$ & $\begin{array}{c}\text { Mailed } \\
(\mathrm{n}=185)\end{array}$ & $\begin{array}{c}\text { Control } \\
(\mathrm{n}=198)\end{array}$ \\
\hline Schools & & & & \\
$\quad$ Kinondoni & 11 & 4 & 4 & 3 \\
$\quad$ Ilala & 8 & 3 & 3 & 2 \\
Temeke & 6 & 3 & 1 & 2 \\
$\quad$ Total & 25 & 10 & 8 & 7 \\
& & & & \\
Teachers & & & & \\
$\quad$ Kinondoni & $272(42 \%)$ & 91 & 90 & 91 \\
llala & $185(28 \%)$ & 60 & 65 & 60 \\
Temeke & $198(30 \%)$ & 50 & 93 & 55 \\
Total & $655(100 \%)$ & 201 & 248 & 206 \\
& & $(31 \%)$ & $(38 \%)$ & $(31 \%)$ \\
\hline
\end{tabular}

A few teachers (15\%) would not take the avulsed tooth to a doctor or dentist (Table 2). No significant differences between the three groups as to whether the teachers would take the avulsed tooth to a doctor/dentist or not. For the teachers who would take an avulsed tooth to a dentist, only $4 \%$ would transport the tooth in milk while $32 \%$ would transport the tooth in saline solution. Scrutiny into individual study groups showed that $47 \%$ of the teachers in a seminar group would transport the avulsed tooth either in milk or saline 
solution, compared to nearly $38 \%$ of the teachers in the mailed guidelines and approximately $31 \%$ in the control group, (Table 3). The difference was highly significant $\left(\mathrm{X}^{2}\right.$ test $\left.\mathrm{P}<0.0005\right)$.

Teachers who would scrub a dirty avulsed tooth to clean it constituted $24 \%$ of the total while those who would use fresh water or saline solution to clean a dirty avulsed tooth were $41 \%$ and $57 \%$ respectively (Table 4). There were no significant differences between the three groups of teachers in the cleaning method or the type of liquid, which they would use to clean a dirty avulsed tooth.

Table 2

Percentage of school teachers reporting various actions they would take when a child sustains a dental injury

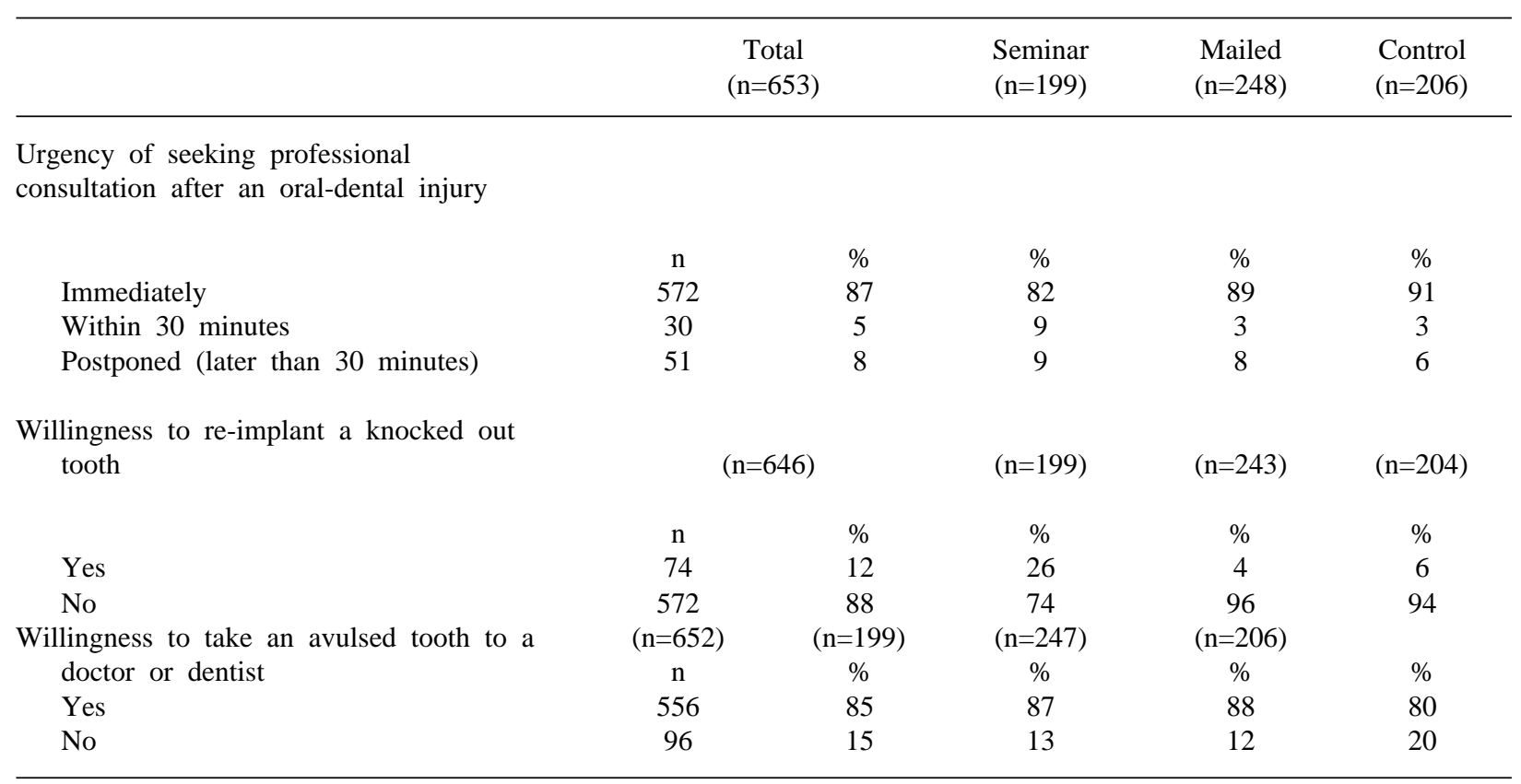

Table 3

Different media that would be used by respondents to transport an avulsed tooth

\begin{tabular}{lccccc}
\hline & $\begin{array}{c}\text { Total } \\
(\mathrm{n}=556)\end{array}$ & $\begin{array}{c}\text { Seminar } \\
(\mathrm{n}=174)\end{array}$ & $\begin{array}{c}\text { Mailed } \\
(\mathrm{n}=217)\end{array}$ & $\begin{array}{c}\text { Control } \\
(\mathrm{n}=165)\end{array}$ \\
\hline In a container with milk & 23 & 4 & 11 & 1 & 2 \\
In a container with salty water & 181 & 32 & 36 & 32 & 29 \\
Wrapped in a plastic bag & 53 & 10 & 7 & 10 & 12 \\
In a container with tap water or juice & 14 & 3 & 0 & 3 & 5 \\
Wrapped in a paper & 245 & 44 & 42 & 44 & 45 \\
Do not know/Others & 40 & 7 & 4 & 10 & 7 \\
\hline
\end{tabular}

Table 4

Liquids that would be used by respondents to clean an avulsed tooth

\begin{tabular}{|c|c|c|c|c|c|}
\hline & \multicolumn{2}{|c|}{$\begin{array}{c}\text { Total } \\
(\mathrm{n}=634)\end{array}$} & \multirow{2}{*}{$\begin{array}{c}\text { Seminar } \\
(\mathrm{n}=195) \\
\%\end{array}$} & \multirow{2}{*}{$\begin{array}{c}\text { Mailed } \\
(\mathrm{n}=239) \\
\%\end{array}$} & \multirow{2}{*}{$\begin{array}{c}\text { Control } \\
(\mathrm{n}=200 \\
\%\end{array}$} \\
\hline & $\mathrm{n}$ & $\%$ & & & \\
\hline Milk & 15 & 2 & 5 & 1 & 1 \\
\hline Saline solution & 359 & 57 & 60 & 58 & 53 \\
\hline Fresh water or juice & 260 & 41 & 35 & 41 & 46 \\
\hline
\end{tabular}


Fifty nine percent reported to have received some advice on what to do in the event of oral trauma. Twenty two percent reported to have received such advice from a dentist. More teachers from the seminar group $(71 \%)$ reported to have received some advice on what to do in the event of injury to oral tissues than teachers from the mailed guidelines group (58\%) or control group $(50 \%)$. This difference was highly significant, $\left(\mathrm{X}^{2}\right.$ test $\left.\mathrm{P}<0.0005\right)$. Similarly, a highly significant difference $\left(X^{2}\right.$ test $\left.P<0.0005\right)$ was observed among teachers from the seminar group (29\%) who reported to have received some advice from their colleagues as compared to $8 \%$ and $7 \%$ for the mailed guidelines and control group respectively.

\section{DISCUSSION}

The current observation that a substantial number of teachers have seen a child who had sustained oraldental injuries supports an earlier report(10), that oral injuries are common among children in Tanzania. Responses for a few questions did not show any statisticaly significant differences among the three study groups. First, was a report of the teachers to have seen children who suffered different types of trauma. Basically, guidelines were not expected to influence this behaviour. The other three responses namely, a method for cleaning of a dirty avulsed tooth, a liquid to be used in cleaning and lack of willingness to take an avulsed tooth to a dentist or doctor were expected to change. Absence of change may imply a need of emphasis or modification in education strategies.

Teachers from the seminar group were more likely to reimplant an avulsed tooth (five times more likely than the control group) or otherwise would transport it in the recommended medium despite the fact that milk was not readily available. Since $32 \%$ of the teachers would transport the avulsed tooth in a salty solution, a reliable approach to promote correct transportation of an avulsed tooth to a dentist would have been to instruct the teachers/lay community on how to prepare a saline solution. More teachers in the seminar group reported to have received some advice on what to do in the event of injury to oral tissues from their colleagues than teachers in the mailed guidelines or control group. These findings indicate that seminars would be a good mode of providing correct information when compared to provision of guidelines by mail.

The current study shows that the school teachers have inadequate knowledge on the management of traumatised teeth, similar to what has been reported in previous studies (1-5). As children spend more time at schools it means that teachers with inadequate knowledge should provide inappropriate initial management to children who sustain dental trauma at school. This is particularly true with regard to the method of cleaning the avulsed tooth, the transport media for an avulsed tooth and the need to take an avulsed tooth to the dentist or doctor. The lack of appropriate knowledge and skills also presents lost opportunities for saving or preserving teeth, which would have a probability of being reimplanted.

Compared to findings of other studies, fewer teachers in the current study ( $4 \%$ ) would transport the avulsed tooth in milk. The percentages in other studies ranged from 4.5 to 10 . Forty two percent of teachers in the current would send a child to a dentist and eleven percent were willing to reimplant an avulsed tooth compared to $62.5 \%$ and $62 \%$ respectively as was reported by Raphael and Gregory (1). The social consequence of this practice is that children would have missing anterior teeth, which would cause a social stigma when smiling or talking. Social stigmata associated with missing anterior teeth may necessitate a demand for dentures at an early age.

The findings of this study correlate well with those of other studies in that the lay community has inadequate knowledge on the management of avulsed teeth. The results show that provision of information through seminar discussions improved school teachers' knowledge on measures to be taken in the event of dental injuries better than through the mailed guidelines. It is recommended that first, a topic about handling of traumatised teeth be incorporated in the school teachers' training curriculum. Secondly, that more seminars be organised for a wider coverage so as to create awareness to the larger Tanzanian population regarding measures to be taken in the event of oral injury.

\section{ACKNOWLEDGEMENTS}

The authors thank all schoolteachers who filled in the questionnaire forms and Mr Kitwana for assistance in data collection. The University of Nijmegen through the WHO Collaborating center for Oral Health Planning and future scenarios sponsored the study.

\section{REFERENCES}

1 Raphael, L.R and Gregory P.J Parental awareness of the emergency management of avulsed teeth in children. Aust Dent J 1990; 35:130-133.

2. Newman, L. and Crawford, P.J.M. Dental injuries: knowledge of Southampton teachers of physical education. Endod Dent Traumatol 1991; 7:255-258.

3. Stokes, A.N., Anderson, H.K. and Cowan, T.M. Lay and professional knowledge of methods for emergency management of avulsed teeth. Endod Dent Traumatol 1992; 8:160-162.

4. Hamilton, F.A, Hill, F.J., and Mackie, I.C. Investigation of lay knowledge of the management of avulsed permanent incisors. Endod Dent Traumatol 1996; 13:19-23.

5. Sae-Lim, V., Chulaluk, K., and Lim, L.P. Patient and parental awareness of the importance of immediate management of traumatised teeth. Endod Dent Traumatol 1999; 15:37-41. 
6. Andreasen, F.M. and Andreasen, J.O. Examination and Diagnosis of dental injuries. In: Andreasen J.O, Andreasen F.M. (1994): Textbook and colour atlas of traumatic injuries to the teeth. $3^{\text {rd }}$ edn. Munksgaard, Copenhagen 1999: 195217.

7. Sae-Lim, V. and Yuen, K.W. An evaluation of after-officehour dental trauma in Singapore. Endod. Dent. Traumatol. 1997; 13:164-170.

8. Moshy, J, Mosha, H.J, and Lema, P.A. Prevalence of maxillo-mandibular fractures in mainland Tanzania. East
Afr Med J 1996; 73:172-175.

9. McTigue, D.J. Managing traumatic injuries in the primary dentition and in the young permanent dentition. In: Pinkham, J.R. Paediatric Dentistry: Infancy through adolescence. 2nd ed Philadelphia, W.B. Saunders Company, 1994; 209-22, 492-504.

10. Kahabuka, F.K, Willemsen, W, van 't Hof M.A., Ntabaye, M.K, Plasschaert A, Frankenmolen F. et al. Oro-dental injuries and their management among children and adolescents in Tanzania. East Afr Med J 1999; 76:160-162.

\section{TREATMENT OF SNAKE BITE SOUTH AFRICAN VACCINE PRODUCERS (PTY) LTD \\ "BUYING FROM AFRICA FOR AFRICA"}

AS AWHOLLY OWNED SUBSIDIARY OF THE NATIONAL HEALTH LABORATORY SERVICES (PREVIOUSLY S.A.I.M.R) S.A.V.P (PTY) LTD IS COMMITTED TO CONTINUE ITS PRODUCTION OF STRATEGIC ANTIVENOM

PRODUCTS, USED SUCCESSFULLY FOR THE TREATMENT OF

ENVENOMATION BY POISONOUS AFRICAN SNAKES. WE HAVE BEEN OPERATIONAL SINCE 1928.

\section{OUR PRODUCTS INCLUDE:}

1) POLYVALENT SNAKE ANTIVENOM T517(ACT 101/1965)

EFFECTIVE AGAINST THE FOLLOWING SPECIES:

Bitis arietans (Puff adder)

Bitis gabonica (gaboon adder)

Hemachatus Haemachatus (rinkhals)

Dendroaspis angusticeps (green mamba)

Dendroaspis polylepsis (black mamba)

Naja nivea (cape cobra)

Naje melanoleuca (forest cobra)

Naje haje annulifera (Egyptian cobra)

Naje mossambica (Mozambican spitting cobra)

2) SPECIFIC BOOMSLANG MONOVALENT ANTIVENOM T 515 (ACT 101/1965)

3) MONOVALENT ANTIVENOM AGAINST THE SAW SCALED VIPER (ECHIS CARINATUS/OCELLATUS) T516(ACT101/1965)

FOR FURTHER INFORMATION PLEASE CONTACT US ON +27 (11)-386 6000 OR

VIEW OUR WEBSITE AT www.savp.co.za 